\title{
TURNOVER OF PUBLIC SECTOR EMPLOYEES AND THE MEDIATING ROLE OF JOB SATISFACTION: AN EMPIRICAL STUDY IN LATVIA
}

\author{
Iveta Ludviga \\ Irina Senņikova \\ Agita Kalvinga \\ RISEBA University, Latvia
}

\begin{abstract}
Public sector reforms in many countries have been related to cost reductions, increased workload and similar issues. Ignoring the impact of reforms on employee job satisfaction may decrease employee engagement and the quality of service delivery. This paper aims to identify the main factors that determine the level of job satisfaction of public sector employees in a developing country and to find out which factors should be addressed first in order to decrease employee turnover. The survey conducted in 2015 included 365 respondents. For data analysis, partial least square structural equation modelling (PLS-SEM) technique is used to test the model and identify the most important factors relevant to turnover intentions. The results indicate a strong relationship between satisfaction factors and intentions to stay. Satisfaction partly mediates the association between career growth possibilities, work environment, attitude of a direct manager, pay as well as social security and intentions to stay. Growth has the strongest total effect on intentions to stay with a public sector organisation. Thus, taking into consideration the cost cuttings and economic situation, career growth and the reward system are the two factors, which should be addressed first. Moreover, pay is the most important factor for the attraction of younger generation employees to the public sector.
\end{abstract}

Keywords: public sector, human resource management, employee satisfaction, turnover, intentions to stay.

\section{Introduction}

Over the last 40 years in Europe and around the world, public sector reforms are an on-going phenomenon. Since the 50's of the 20th century, public sector developments can be characterized by significantly different features and expressions and we can follow through three main stages. The first is the traditional Public Administration stage (Huges, 2003); since the 1970's until the end of the 1990's the so-called New Public Management stage followed (Hood, 1991; Turkylmaz et.al., 2011). The New Public Management (NPM) ideology of treating a government as if it were a business has informed many changes in many countries; however, some argue that it has already become 
obsolete. Western scholars call the period since the 1990-ies the New Public Governance (Bovaird \& Loffler, 2005; Eliassen \& Sitter, 2008; Meuleman, 2008; Pollitt \& Bouckaert, 2011). Recently it has been argued that the New Public Governance (NPG) has become the dominant regime of public policy implementation and public service delivery (Osborn, 2010, p. 414).

On the backdrop of all these developments, among primary problems raised by modern public administration there is the question how to respond to developmental changes, how to implement new approaches and modern characteristics of new public management (Cankar \& Petkovsek, 2014). The global recession has introduced new public sector reforms in many countries, including cost reductions, restructurings, activities with purpose to increase efficiency and effectiveness, an increased workload, introduction of new management tools like performance management, performance related pay and other similar changes. Public sector reforms are generally aimed at management that is more effective and efficient. The necessity of these reforms may not be questioned. However, ignoring the impact of reform implementation on employee motivation and job satisfaction may decrease employee engagement and the quality of service delivery. This, in its turn, can lead to high turnover in the public sector and even the loss of trust in public administrators.

Latvia, like other post-communist countries in the early 1990s, by launching its administrative reform, had to master the principles of democratic countries' traditional bureaucracies as well as to keep up with the latest modernization trends in public administration. According to recent data on the public sector, the efficiency and management of state-owned enterprises has significantly improved. A public administration efficiency rating expressed from 0 to $100 \%$, which is the highest rating, in Latvia from $61 \%$ in 1996 climbed to $76 \%$ in 2013, and is well ahead of the National Development Plan control indicator in 2014. Still there is place to grow up to the 2020 target of $85 \%$. According to Global Competitiveness Index (GCI) sub-index "public institutions", Latvia is ranked $52^{\text {nd }}$ out of 144 countries (Schwab, 2015). The single remuneration system in the public administration is mentioned among the brightest state administration reforms. Since the government is also the European Union's priority, the European Commission recommends Latvia to further strengthen the public administration reform, including the implementation of corporate governance reforms. The International Monetary Fund agrees and recommends centralizing the management of state-owned enterprises, while getting rid of the supporting activities (Rutkovska, 2015).

Because of all the reforms and changes, public sector organisations in Latvia feel pressure with regard to delivering high quality services. Public sector organisations have shown increasing interest in introducing various human resource management tools, including employee evaluation and job satisfaction. 
The latest becomes especially important because many public sector organisations recently faced a high employee turnover and even a severe lack of qualified employees. In a situation when extrinsic motivators, like pay, are constrained or even reduced, complex approaches become more important. Latvia is not actually investing in public sector research to serve as the basis for different decision-making in public administration. It is necessary to carry out research studies regularly on this nationally important sector and to base decisions on these studies.

This paper presents an empirical study of employee satisfaction and its impact on turnover in a large Latvian public sector organisation. It aims to identify the main factors which determine the level of job satisfaction of public sector employees and identify a variable that might have an impact on turnover intentions of public sector employees, mainly to find out which factors should be addressed first by management in order to decrease employee turnover. The paper explores whether intentions to stay with a public sector organisation can be fostered by the application of such HR practices as support employees receive from the organisation and talent management.

To achieve the aim, the case study strategy was chosen and quantitative data gathered using structured on-line survey. For data analysis, partial least square structural equation modelling (PLS-SEM) technique was used and the model designed.

This research study contributes to HRM literature on several aspects. It is one of the first research studies on the Latvian public sector to investigate turnover intentions; moreover, it is one of few research studies investigating the mediating effect of satisfaction on turnover and the moderation role of age on satisfaction and turnover. The paper is structured as follows. First, theoretical aspects of employee satisfaction and loyalty with respect to public sector specifics are discussed. Relationships between different factors of satisfaction and loyalty are identified and hypotheses related to these relationships are developed. The hypotheses are tested by means of a variance based structural equation model with the Smart PLS software. The paper ends with the evaluation of results, discussion and conclusions.

\section{Theoretical framework and research questions}

Many researchers have investigated causes of employee turnover and concluded that turnover intentions heavily depend on human resource management practices and job satisfaction is of utmost importance (Sajjad, et al., 2013). Job satisfaction is in an antecedent to organisational loyalty and intentions to stay (Turkyilmaz, et al., 2011). Job satisfaction has been defined as a positive feeling about one's job. Locke defined job satisfaction as "the 
pleasurable emotional state resulting from the appraisal of one's job as achieving or facilitating the achievement of one's job values" (Locke, 1969, p. 316). Gordon defined it as "employee's reaction to what he or she receives from the job" (Gordon, 2011, p. 191).

Previous studies on staff satisfaction and job performance in the profit and public sector organisations have yielded differing results. Therefore, it is essential to focus on the specifics of the public sector organisations. The nature of the job and consequently the feelings of public sector employees are specific. Job satisfaction is an important indicator of how employees feel about their job and, among other things, the predictor of turnover (Kumari \& Pandey, 2011). Public sector employees have different job motivations and work values (Turkyilmaz, et al., 2011). Kumar and Pandey (2011) state that in public sector institutions, compared to private sector firms, the organisation and separation of departmental power is very strict. Public sector employees have to exhibit transparency and the objectives are indefinite. Another peculiarity is elected representatives. The public sector has serious extrinsic motivators, such as security of tenure, career development opportunities and the pension system. Quality of live is also identified as an attraction to the public sector, as many people believe it offers better flexibilities if compared with the private sector (O`Riordan, 2013).

Summarising previous research studies on the public sector, several predicting factors of employee satisfaction and intention to stay are commonly used. Attitude of a supervisor or manager, salary, recognition, rewards and promotions, career development and training programmes, working conditions are the most frequently used constructs (Turkyilmaz, et al., 2011; Steijn, 2002; Bodur, 2002; Gupta \& Sharma, 2009; Kim, 2009; Cankar \& Petkovsek, 2014; Kim, 2002; Yang \& Kasseket, 2009; Sajjad, et al., 2013). Taking into consideration O`Riordan (2013), social security should be included. Since the public sector has to work under the "public eye" (Kumari \& Pandey, 2011), transparency could be expected also from the organisations. Therefore, the transparency of pay and the award system might be an important factor as well.

All the above-mentioned constructs were included in the research model and the following research questions were formulated:

RQ1: Which constructs are the best predictors of employee satisfaction in the public sector organisations?

RQ2: Which constructs are the best predictors of employee intentions to stay in the public sector organisations?

RQ3: Is job satisfaction a strong mediator? Between which construct and intentions to stay job satisfaction is the strongest mediator?

RQ4: Which factors are the most important determinants of satisfaction and intentions to stay for younger employees? 


\section{Data and Methodology}

A case study was used to collect the data and one of the largest public sector organisations in Latvia was chosen. This organisation has been reorganised as part of public sector reform and faces both a high employee turnover and a lack of qualified employees. At the end of 2014, the total number of employees was slightly above 4300; however, the total number of job vacancies was more than 300 . The organisation constantly faces problems with the attraction of young and prospective employees. The average age of employees in the organisation in 2014 was above 40 years.

The model including nine factors determining employee satisfaction relevant to the public sector and turnover measured by intentions to leave and recommendations to the employer was developed. The survey instrument, a structured questionnaire including 11 constructs with 2 to 6 questions referring to each of them and six demographic type questions, was designed. All items, except overall job satisfaction, were measured on a 4-point Likert-type scale, where $1=$ strongly disagree; $2=$ disagree $3=$ agree and $4=$ strongly agree. The scale does not have a neutral answer, as in the Latvian environment, it is recommended not to use a neutral answer due to the high possibility of receiving too many neutral answers. Below the constructs, their coding, number of corresponding questions and their definitions are described.

Working environment (ENV) is initially measured with 4 statements and refers to physical working environment factors, such as a comfortable and clean workplace, lighting, temperature, office space, technical equipment etc. A sample statement reads, "I am very comfortable with my physical work environment'. Career growth potential (GROW) is measured with 4 questions, and this construct measures career development opportunities existing within the organisation and whether employees are informed about them. A sample item forming this scale is "I feel there are good career growth possibilities for me in this organisation". Training and learning (LEARN) with 4 questions measures the quality and applicability of training provided within the organisation. Questions included "Knowledge gained in a training session is applicable to my job". Management (MAN) dimension includes 6 statements and measures the attitude of direct managers towards employees, including respect, a clear explanation of tasks and aims, trust. A sample item from this scale is "My direct manager appreciates my work". Pay (PAY) with 5 questions measures the adequateness and competitiveness of a salary. A sample statement is "My salary is relevant to my contribution". Transparency of Pay system (PAYT) with 2 questions measures the transparency and fairness of the pay system. A statement reads, "I understand the principles of remuneration in the public sector". Bonuses (BON) scale initially had 5 questions and is related to the transparency 
and fairness of bonuses. For example, "Bonuses are always given on a fair basis". Awards (AWAR) dimension with 3 statements measures the transparency and adequateness of monetary awards. For example, "Awards are always based on excellent job results". Social security (SOC) scale has 3 questions and refers to the perceived competitiveness of the social security package "My organisation ensures a competitive social security package". Employee turnover is measured as respondents`intention to stay (IS) with 5 questions which refer to willingness to stay in the organisation and willingness to recommend it as a good place where to work. A sample statement is "I am not actively searching for another job". Overall satisfaction is measured on a 7-point scale where $1=$ 'completely unsatisfied', but $7=$ 'completely satisfied'. This scale refers to employee satisfaction with the work in the organisation in general and the statement is "Please indicate your satisfaction with your current job". Some statements in the questionnaire were reversed to match the direction of other statements and scales and avoid confusion.

The survey was conducted electronically in 2015 and included in total 470 respondents. However, quite many of the respondents had never participated in any kind of training, therefore, were not able to answer questions about training and learning. Since this construct, in line with growth possibilities, was initially considered as a very important predictor of intentions to stay, therefore only full questionnaires were retained for analysis. Besides, some questionnaires had missing answers and were excluded from analysis. The final number of observations included in the model for analysis was 365 .

\section{Findings and data analysis}

For data analysis, variance based structural equation modelling (PLS-SEM) technique was used to test the model and to predict the most important factors relevant to turnover intentions. A particular technique was chosen because it implies the features of multiple regression and does not assume the normality of data distribution, and a K-S test performed with SPSS indicated that data were not normally distributed. Besides, this technique allows including a larger number of indicators and several different scale types (Hair, et al., 2011). The statistical objective of PLS-SEM is to maximize the explained variance of endogenous latent constructs or dependent variables.

The model included two endogenous constructs - IS (intention to stay) and SAT (satisfaction), as well as nine exogenous constructs - ENV (work environment); GROW (career growth opportunities); LEARN (training and learning); PAY (remuneration), PAYT (transparency of remuneration system); MAN (management) and BON (bonuses); AWAR (awards); SOC (social security). All the constructs were measured with reflective type questions. 
To evaluate reflectively measured models, the following should be examined: outer loadings (size and significance); composite reliability; average variance extracted (AVE) or convergent validity; discriminant validity (Hair, et al., 2011). In order to do so, the model is designed by means of Smart PLS software and algorithms calculated. Path coefficients and outer loadings of the model are presented in Figure 1.

Outer model results. The outer model shows how correctly each construct is measured or how each set of indicators is related to their latent variable. As seen in Figure 1, all loadings are above the minimum threshold value of 0.708. However, Figure 1 shows the model with already deleted items. Three items (env1, bon4 and bon5) initially had a loading of 0.4 , therefore, after examining the questions, it was decided to exclude them from the model. The remaining manifest variables exhibit outer loadings high enough and are a good measure of their latent variables. The bootstrapping procedure was used to determine statistical significance. All the loadings were statistically significant.

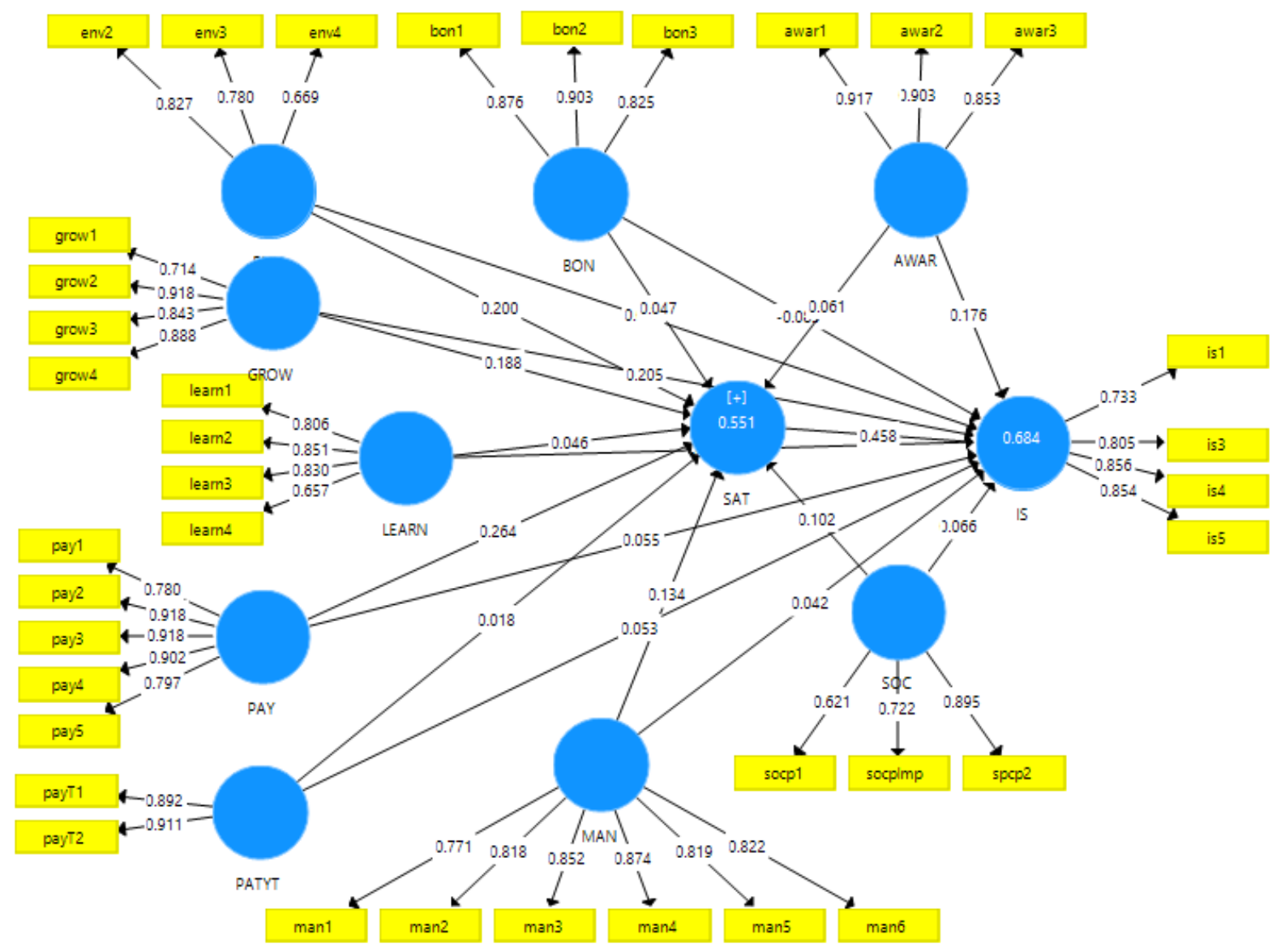

Figure 1 Path coefficients and outer loadings of the model (authors` construction)

Convergent Validity of the reflective constructs is examined with average communality or AVE (average variance extracted). It should be at least higher 
than 50\%. In the model, AVE scores are as follows: AVE: AWAR 0.795; BON 0.754; ENV 0.580; GROW 0.713; IS 0.662; LEARN 0.624; MAN 0.683; PATYT 0.813; PAY 0.748; and SAT 1.000 (since it is measured by one question); SOC 0.569 . All the scores are above 0.5 and thus are acceptable.

Composite Reliability is an estimate of constructs internal consistency and should be above the threshold level of 0.7. Composite reliability scores of the model are as follows: AWAR 0.921; BON 0.902; ENV 0.804; GROW 0.908; IS 0.886; LEARN 0.868; MAN 0.928; PATYT 0.897; PAY 0.937; SAT 1.000 (since it is measured by one question); SOC 0.795 . Composite reliability scores are well above the minimum of 0.7 , thus indicating sufficient reliability.

Discriminant Validity represents the extent to which measures of a given construct differ from the measure of other constructs in the same model. The Heterotrait-Monotrait (HTMT) ratio of correlations is used to measure discriminant validity (Hair, et al., 2011). HTMT is a ratio of correlations within constructs to correlations between constructs. All HTMT values should be lower than 0.85 for conceptually distinct constructs, such as work environment perceptions and management, and lower than 0.9 for conceptually more similar constructs such as satisfaction and intentions to stay. All the HTMT values of the model appeared to be lower than 0.85 , thus, the validity was confirmed. Besides, Bias Corrected confidence intervals showed that neither the high nor the low confidence intervals included a value of 1 . Thus, the discriminant validity is demonstrated by the HTMT method.

Inner model results. The primary evaluation criteria for SEM are $\mathrm{R}^{2}$ results. $\mathrm{R}^{2}$ values of $0.75,0.50$ and 0.25 for endogenous latent variables indicate substantial, moderate or weak predicting capacity (Hair, et al., 2011). The model had $\mathrm{R}^{2}(\mathrm{IS})=0.68$ and adjusted $\mathrm{R}^{2}=0.67 ; \mathrm{R}^{2}$ (SAT) $=0.55$ adjusted $\mathrm{R}^{2}=0.54$, thus the model has an above-moderate predicting capacity.

All the relationships between the latent variables (except two nonsignificant relationships) are positive. Thus, for each of the relationships, an increase in the value of an independent latent variable is associated with the increase in the value of a dependent latent variable. The highest statistically significant path coefficients are SAT-IS (0.46); ENV-SAT (0.2); PAY-SAT (0.26); GROW-SAT (0.2); GROW-IS (0.2), as seen in Table 1.

The individual paths coefficients of the PLS structural model are interpreted as standardised beta coefficients of OLS regressions (Hair, et al., 2011). Data analysis reveals a strong relationship between satisfaction and turnover intentions. Only three factors out of the nine included in the model appeared to have a significant relationship with employee intention to stay. The work environment, growth (potential for personal development) and the award system were found the most effecting factors. Still five factors exhibit a 
significant relationship with satisfaction - the work environment, growth, management, pay and social security.

Table 1 Inner model results (author`s calculations)

\begin{tabular}{|l|c|c|c|c|}
\hline \multirow{2}{*}{ Construct } & \multicolumn{2}{|c|}{ SAT } & \multicolumn{2}{c|}{ IS } \\
\cline { 2 - 5 } & Path Coefficient & P Value & Path Coefficient & P Value \\
\hline BON & 0.047 & 0.447 & -0.083 & 0.076 \\
\hline ENV & $\mathbf{0 . 2 0 0}$ & $\mathbf{0 . 0 0 0}$ & $\mathbf{0 . 0 7 8}$ & $\mathbf{0 . 0 4 1}$ \\
\hline GROW & $\mathbf{0 . 1 8 8}$ & $\mathbf{0 . 0 0 0}$ & $\mathbf{0 . 2 0 5}$ & $\mathbf{0 . 0 0 0}$ \\
\hline LEARN & 0.046 & 0.277 & -0.002 & 0.953 \\
\hline MAN & $\mathbf{0 . 1 3 4}$ & $\mathbf{0 . 0 0 4}$ & 0.042 & 0.289 \\
\hline PAY & $\mathbf{0 . 2 6 4}$ & $\mathbf{0 . 0 0 0}$ & 0.055 & 0.277 \\
\hline PAYT & 0.018 & 0.757 & 0.053 & 0.204 \\
\hline SOC & $\mathbf{0 . 1 0 2}$ & $\mathbf{0 . 0 1 9}$ & 0.066 & 0.068 \\
\hline AWAR & 0.061 & 0.279 & $\mathbf{0 . 1 7 6}$ & $\mathbf{0 . 0 0 0}$ \\
\hline SAT & na & na & $\mathbf{0 . 4 5 8}$ & $\mathbf{0 . 0 0 0}$ \\
\hline
\end{tabular}

Mediation Analysis. A PLS-SEM technique is especially useful to evaluate a direct effect, an indirect effect and a total effect. In order to understand between which construct and intentions to stay (IS) satisfaction (SAT) is a strong or moderate mediator, we run the model without SAT and received the path coefficients for an indirect effect. Then we run the model with satisfaction (SAT) and got path coefficients for a total effect. This allows calculating variance accounted for (VAF), which is variance accounted for (explained) in the dependent variable by the indirect relationship. Table 2 presents indirect and total effects, as well as mediation strengths. If an indirect effect is significant, there is mediation.

Table 2 Total effect and variance accounted for mediation (authors`calculations)

\begin{tabular}{|c|c|c|c|c|c|c|}
\hline Effect & \multicolumn{2}{|c|}{ Indirect effect } & \multicolumn{2}{|c|}{ Total effect } & \multirow{2}{*}{$\begin{array}{c}\mathrm{VAF} \\
\%\end{array}$} & \multirow[b]{2}{*}{$\begin{array}{l}\text { Mediation } \\
\text { strengths }\end{array}$} \\
\hline Construct & $\begin{array}{l}\text { Path } \\
\text { coefficient }\end{array}$ & $\mathrm{p}$ Values & $\begin{array}{l}\text { Path } \\
\text { coefficient }\end{array}$ & p Values & & \\
\hline ENV $\rightarrow>$ IS & 0.092 & 0.000 & 0.170 & 0.000 & 54.1 & partial mediation \\
\hline GROW -> IS & 0.086 & 0.001 & 0.291 & 0.000 & 29.6 & partial mediation \\
\hline MAN -> IS & 0.061 & 0.006 & 0.104 & 0.015 & 58.7 & partial mediation \\
\hline PAY $\rightarrow>$ IS & 0.121 & 0.000 & 0.175 & 0.002 & 69.1 & partial mediation \\
\hline SOC $->$ IS & 0.047 & 0.023 & 0.112 & 0.006 & 42.0 & partial mediation \\
\hline
\end{tabular}


Growth has the strongest total effect on intentions to stay followed by pay. Thus we can conclude that satisfaction partly mediates the relationship between IS and ENV, GROW, MAN, PAY and SOC.

Multi-group analysis. Multi-group analysis allows comparing parameters such as path coefficients between two or more groups when the groups are known. Since public sector organisations in Latvia are especially interested in attracting young employees, a multi-group analysis is performed between 5 age groups. The question to be answered is "which factors are the most important determinants of satisfaction and intentions to stay for younger employees?"

The multi-group analysis revealed that statistically significant path coefficients for employees under 30 were GROW -> IS (0.27); PAY -> SAT (0.35) and SAT -> IS (0.45). The GROW -> IS relationship is important for every second age group. Interestingly that the relationship MAN $\rightarrow$ SAT becomes significant only for the older generation of employees. PAY $\rightarrow$ SAT is important only for employees up to 50 years of age, after it loses the importance. PAY is not related to IS for all generations.

\section{Discussion}

The overall objective of this research study was to identify the main factors that determined the level of job satisfaction of public sector employees and to find out which factors should be addressed by management first in order to decrease employee turnover in the Latvian public sector.

The SEM technique allowed to study direct and indirect effects of constructs', as well as total effects on intentions to stay with the organisation. Job satisfaction was used as a mediating variable. Overall, the chosen constructs and model appeared to have moderate predicting power and the adjusted $\mathrm{R}^{2}$ indicates that $67 \%$ of employee intentions to stay with the organisation and $54 \%$ of job satisfaction can be explained by the included constructs.

In this research study, the career growth was found to be the most important factor affecting employees` intentions to stay with the organisation with a total effect standardized regression weight of $0.29(\mathrm{p}<0.01)$ and a direct effect path coefficient of $0.205(\mathrm{p}<0.01)$. This result is consistent with O'Riordan (2013) who said that career development opportunities are among the factors employees traditionally expect from the public sector. In respect to job satisfaction, growth is ranked third with a path coefficient of $0.188(\mathrm{p}<0.01)$.

Interestingly, that training and learning, which naturally is associated with career growth, appeared to have no effect on intentions to stay as well as on job satisfaction ( $p>0.05)$. However, other research studies that combined training and personal development in one construct have found it to be significant (Turkyilmaz, et al., 2011). 
Implications for public sector organisations are that they need to create a work environment in which employees perceive support in their career development aims. Talent management practices should be introduced by HR departments and clearly communicated to all employees, even the newcomers. Career plans for all employees should be created and career opportunities discussed during annual evaluations. Organisations should re-evaluate the provided training programmes and, probably, change them to better link them to career growth needs of employees.

The second most important factor on intentions to stay was found to be the work environment with a total effect of $0.17(\mathrm{p}<0.01)$. The work environment has also a significant effect on job satisfaction with a standardized regression weight of $0.20(p<0.01)$. This result is consistent with the conclusions of Turkyilmaz (2011) who suggests that satisfaction can be raised by the ergonomic design of a workplace. The work environment includes such working conditions as a satisfactory workspace, cleanness, appropriate lighting, office equipment, temperature and similar things important for everyday job.

Pay was found to be the third important construct that effect intentions to stay with a total effect path coefficient of $0.264(\mathrm{p}<0.05)$. It is also a very important creator of job satisfaction with a standardized regression weight of 0.264 ( $\mathrm{p}<0.01)$. Interestingly, that pay has no significant direct effect on intentions to stay, with job satisfaction mediating the relationship. These results allow drawing conclusions about the Latvian public sector's single remuneration system reform. The system itself provides a transparent structure of job grades and requirements and allows having a coherent and equal approach to setting pay levels in all public sector organisations, which is very important in respect of job satisfaction. However, what needs to be addressed urgently is the pay level itself, which since the crises period and consolidation activities made by the government has significantly dropped below the market's average. The newly introduced performance management systems put high focus on result implementation and thus adjustments in the pay system could be made introducing a stronger link between performance and pay.

Interestingly that awards are linked to pay and have a significant direct effect on intentions to stay with a path coefficient of $0.176(\mathrm{p}<0.01)$, but no effect on job satisfaction ( $p>0.05$ ). Awards mean the recognition of excellence of a particular employee. Consequently, if an employee feels that he or she has outstanding achievements and excellent performance but is not awarded for that, the employee may feel offended and leave the company. Managers in public sector organisations should be aware of the importance of awards and recognitions, and the reward system should be based on individual performance and be fair and just towards all employees. This finding is in line with that by 
Erturk (2014) who found that recognition was one of the most important HR practice for public sector IT employees.

Finally, an immediate management attitude with a path coefficient of 0.104 $(\mathrm{p}<0.05)$ appeared to have a significant total effect on intentions to stay. However, a direct effect is not significant and job satisfaction serves as a mediator. Management with a path coefficient of $0.134(\mathrm{p}<0.05)$ was found to have the fourth most significant effect on job satisfaction. This finding is in line with that by Nohria (Nohria, et al., 2008) who indicated that supervisors might foster the motivating local environment even if the organisation as a whole was not then the best one. However, the multi-group analysis revealed that this construct was a significant predictor of job satisfaction only for the age group of 56 and above. For younger generation employees, management attitude was significant neither for job satisfaction nor for intentions to stay.

It was expected that in the public sector a better social security package might be a significant factor effecting intention to stay, and it appeared to be a significant predictor of job satisfaction with a path coefficient of $0.102(\mathrm{p}<0.05)$ and also have a total effect on intentions to stay with a path coefficient of 0.112 $(p<0.05)$, but no direct effect. In this case, job satisfaction serves as a mediator.

Job satisfaction is important, as it partly mediates a relationship among the work environment, growth opportunities, management, pay and social security and intentions to stay with the organisation. The path coefficient between satisfaction and intention to stay is significant and the highest in the model at $0.458(\mathrm{p}<0.01)$. For public sector organisations, satisfaction with the job has a direct impact not only on the time they spend working for the organisation but also on the quality of services provided.

Public sector organisations are willing to recruit specialists of younger generation; however, it is a well-known fact that younger generations are motivated by different factors, compared with other generations. The multigroup analysis revealed that for employees younger than 30 years, pay is the most important factor with a standardized regression weight of $0.448(\mathrm{p}<0.01)$ with respect to staying with the organisation and $0.35(\mathrm{p}<0.01)$ with respect to job satisfaction. This is in line with other generation research studies done in Latvia. Career growth is the second most important factor for staying with a path coefficient of $0.273(\mathrm{p}<0.01)$. All the other factors for younger generation employees appeared to be statistically insignificant. Implications of this finding for the public sector is that, taking into consideration that salary might not be under control of the organisation, clear career growth paths and opportunities should be envisaged for young employees already during the introduction period. A clear understanding of what career path the public sector may offer for a young employee might be the crucial factor why he or she chooses the particular employer and stays with the organisation. 


\section{Conclusion}

The paper reveals the relationship between factors forming employee satisfaction and turnover in the public sector in Latvia and identifies the most important factors. Taking into consideration the cost cuttings and economic situation, career growth and personal development and the work environment are the two factors that should be addressed first by the management of a public sector organisation since they have the strongest relationship for intentions to stay with the organisation. Career growth is important also for the younger generation, and for them it is the only factor, which might be influenced objectively.

PLS-SEM appeared to be a useful technique, as it allowed revealing direct effects, indirect effects and total effects of the constructs on a latent variable. It also allowed measuring the strengths of mediation and performing the multigroup analysis.

The research study, however, is subject to some limitations. The research is based on a particular organisation and the case study approach, therefore the findings cannot be generalised to the whole population of public sector employees. The case study was preferred to a large-scale quantitative survey due to the sensitive nature of the subject. Another limitation is connected with the included constructs. Although nine factors were included in the model, it cannot be claimed that these factors are the only possible predictors of job satisfaction and intentions to stay. Other important factors might be relevant, like, for example, public service motivation. Thus, there is a vast arena of future research.

In spite of the above limitations and context specificity of the results, this research study contributes to the academic literature and HR professionals, since it is performed in the public sector organisation in a developing country. Public institutions in other post-socialist countries may experience similar dynamics and thus the findings of this research study may be of interest to HR professionals from other countries. The public sector has a major role to play in the development of any country, thus any kind of research on this sector has a wider impact and could not be overestimated.

\section{References}

Bodur, S., 2002. Job satisfaction of health care staff employed at health care in Turkey. Occupational medicine, 52(6), 353-355.

Bovaird, T. \& Loffler, E., 2005. Public Management and Governance. London: Routledge.

Cankar, S. \& Petkovsek, V., 2014. Measuring Employee Satisfaction in Public Sector Organisations: A Case Study from Slovenia. Munich, The Clute International Academic Conference. 
Iveta Ludviga, Irina Sennikova, Agita Kalvina. Turnover of Public Sector Employees and the Mediating Role of Job Satisfaction: an Empirical Study in Latvia

Chang, C. C., Chiu, C. M. \& Chen, C. A., 2010. The effect of TQM practices on employee satisfaction and loyalty in government. Total Quality Management \& Business Excellence, 21(12), 1299-1314.

Eliassen, K. A. \& Sitter, N., 2008. Understanding Public Management. Ed.1.: SAGE Publications.

Erturk, A., 2014. Influences of HR Practices, Social Exchange, and Trust on Turnover Intentions of Public IT Professional. Public Personnel Management, 43(1), 140-175.

Gordon, V., 2011. Exploring the job satisfaction of municipal clerks. Review of Public Personnel Administration, Volume 31, 190-208.

Gupta, M. \& Sharma, P., 2009. Job satisfaction level among employees: a case study of Jammu region, J\&K. The Icfain Journal of Management Research, 8(5), 17-25.

Hair, J. F., Ringle, C. M. \& Sarsdet, M., 2011. PLS-SEM: Indeed a silver bullet. Journal of Marketing theory and Practice, 19(2), 139-151.

Hood, C., 1991. A public management for all seasons. Public Administration, 69(1), p. 319.

Huges, O. E., 2003. Public Management and Administration. New York: Palgrave Macmillian.

Yang, K. \& Kasseket, A., 2009. Linking management reform with employee job satisfaction: evidence from federal agencies. The Journal of Public Administration Research and theory, Volume 20, 423-436.

Kim, S., 2002. Participative management and job satisfaction: lessons for management leadership. Public Administrative review, 62(2), 231-241.

Kim, S., 2009. IT employee job satisfaction in the public sector. International Journal of Public Administration, Volume 32, 1070-1097.

Kumari, G. \& Pandey, K. M., 2011. Job satisfaction in Public Sector and Private Sector: A Comparison. International Journal of Innovation and Technology, 222-228.

Locke, E. A., 1969. What is job satisfaction. Organisational Behaviour and Human Performance, Volume 4, 309-336.

Meuleman, L., 2008. Public management and metagovernance of hierarchies, networks and markets: the feasibility of designing and managing governance style combinations. Ed.1.:Springer.

Nohria, N., Groysberg, B. \& Lee, L. E., 2008. Employee Motivation: A Powerful New Model. Harvard Business Review, Volume July-August.

O`Riordan, J., 2013. Public Service Motivation, Dublin: Institute of Public Administration.

Osborn, S., 2010. The new Public Governance: emerging perspectives on the theory and practice of public governance. London and New York: Taylor and Francis.

Politt, C. \& Bouckaert, G., 2011. Public management reform: a comparative analysis: New Public management, Governance and NeO-Weberian State. Oxford: Oxford University Press.

Rutkovska, A., 2015. Makroekonomika.lv. [Online] Available at: https://www.makro ekonomika.lv/strukturalas-reformas-latvija-bez-skalpela-neiztikt-2-dala [Accessed 28 October 2015].

Sajjad, A., Ghazanfar, H. \& Ramzan, M., 2013. Impact of Motivation on Employee Turnover in Telecom Sector of Pakistan. Journal of business Studies Quarterly, 5(1),. 76-92.

Schwab, K., 2015. The Global Competitiveness Report 2014-2015, Ed.1.: Word Economic Forum.

Steijn, B., 2002. HR and job satisfaction in Dutch public sector M. Potsdam, 4-7 September, Study Group on Public Personnel Policies. 
SOCIETY. INTEGRATION. EDUCATION

Proceedings of the International Scientific Conference. Volume IV, May $27^{\text {th }}-28^{\text {th }}$, 2016. 364-378

Turkyilmaz, A., Akman, G., Ozkan, C. \& Pastiszak, Z., 2011. Empirical study of public sector employee loyalty and satisfaction. Industrial management and Data Systems, 111(5), 675-693. 